\title{
Letter to the Editor: The Chitranjan Ranawat Award: Running Subcuticular Closure Enables the Most Robust Perfusion After TKA: A Randomized Clinical Trial
}

\author{
Mitchell S. Fourman MD, M.Phil, Brett T. Phillips MD, MBA
}

To the Editor,

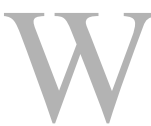

e would like to praise the impressive methodology and unique approach of Wyles and colleagues [6] in their evaluation of intraoperative blood flow measurements of TKA using indocyanine green (ICG) dye angiography. While their evaluation showed that

(RE: Wyles CC, Jacobson SR, Houdek MT, Larson DR, Taunton MJ, Sim FH, Sierra RJ, Trousdale RT. The Chitranjan Ranawat Award: Running Subcuticular Closure Enables the Most Robust Perfusion After TKA: A Randomized Clinical Trial. Clin Orthop Relat Res. 2016;474:47-56).

The authors certify that neither they, nor any members of their immediate families, have any commercial associations (such as consultancies, stock ownership, equity interest, patent/licensing arrangements, etc.) that might pose a conflict of interest in connection with the submitted article. All ICMJE Conflict of Interest Forms for authors and Clinical Orthopaedics and Related Research ${ }^{\circledR}$ editors and board members are on file with the publication and can be viewed on request.

The opinions expressed are those of the writers, and do not reflect the opinion or policy of $C O R R^{\circledR}$ or The Association of Bone and Joint Surgeons ${ }^{\circledR}$. perfusion differences after primary closure likely do not contribute to wound complications, the authors did note that ICG angiography may have a critical role to play in the closure of more vulnerable surgical sites in patients with poor soft-tissue quality or wound-healing capacity.

The authors promote their methodology for evaluation of wound blood flow as "first in its class", using absolute objective measurements provided by the SPY-Elite (Novadaq, Bonita Springs, FL, USA) device in their comparison of perfusion outcomes.

However, we caution the authors that quantitative blood flow measurements by plastic surgeons when

M. S. Fourman MD, M.Phil ( $₫)$

Department of Orthopaedic Surgery,

University of Pittsburgh Medical Center,

Suite 911 Kaufmann Medical Building,

3471 Fifth Avenue, Pittsburgh, PA

15213, USA

e-mail: FourmanM@upmc.edu

B. T. Phillips MD, MBA

Division of Plastic Surgery, Department

of Surgery, Duke University Medical

Center, Durham, NC, USA managing complex wound closure situations during breast reconstructions have been well described for nearly a decade. A quantitative threshold of 23.8 arbitrary perfusion units for partial thickness necrosis using the SPY-Elite was validated by Phillips and colleagues [5] in 2014. We further believe that an acute analysis of staple and suture closure with ICG angiography assesses vasospastic, traumatized tissue, which may be a poor predictor of longterm skin survival. If the pure vascular changes associated with wound closure are sought, analysis longer than 1 hour after the procedure may be more representative of actual tissue blood flow. Wound closure essentially creates a "second hit" trauma to the local tissue and could further influence perfusion analysis. We also propose that decreased perfusion away from the incision portends a higher potential for necrosis at the wound edge, as this is where the blood flow to the incision originates. Finally, visible sutures and staples serve as signal artifacts that may skew local and region-of-interest tissue measurements. 
Normalization between samples is a considerable challenge when comparing the quantitative ICG fluorescence of two wounds. While intravenous injection makes the delivery of ICG somewhat more consistent between patients, it does not adequately control for metabolism and tissue thickness. Our group previously proposed using the maximum quantitative blood flow measured in normal tissue within the field of view as a common normalization point [1]. For any points or regions of interest highlighted within an active field, the maximum normal tissue value adjusts for delivery variance, permitting multifield and between-sample comparisons. This has been successfully applied in the quantitative, prognostic evaluation of burn wounds [2], artificial dermis invasion [3], and the diagnosis of early flap venous congestion [4]. We believe that any normalization should be based on prior models, permitting us to avoid reinventing the wheel for ICG angiography in orthopaedics.
We thank Wyles and colleagues for being the first to truly define a utility for ICG angiography in the field of orthopaedic surgery. Improved blood flow is increasingly recognized as a critical factor in the advancement of ideal orthopaedic surgery practices. We hope that the authors will consider the lessons taught by plastic surgeons as they continue to pursue new ways to use this game-changing technology.

\section{References}

1. Fourman MS, Gersch RP, Levites HA, Phillips BT, Bui DT. Is there a right way to interpret SPY? Normalization of indocyanine green angiography readings in a burn model. Plast Reconstr Surg. 2015;136:128e$130 \mathrm{e}$.

2. Fourman MS, Phillips BT, Crawford L, McClain SA, Lin F, Thode HC, Jr., Dagum AB, Singer AJ, Clark RA. Indocyanine green dye angiography accurately predicts survival in the zone of ischemia in a burn comb model. Burns. 2014;40:940-946.
3. Fourman MS, Phillips BT, Fritz JR, Conkling N, McClain SA, Simon M, Dagum AB. Laser-assisted indocyanine green dye angiography accurately predicts the split-thickness graft timing of integra artificial dermis. Ann Plast Surg. 2014;73:150155.

4. Nasser A, Fourman MS, Gersch RP, Phillips BT, Hsi HK, Khan SU, Gelfand MA, Dagum AB, Bui DT. Utilizing indocyanine green dye angiography to detect simulated flap venous congestion in a novel experimental rat model. $J$ Reconstr Microsurg. 2015;31:590-596.

5. Phillips BT, Fourman MS, Rivara A, Dagum AB, Huston TL, Ganz JC, Bui DT, Khan SU. Comparing quantitative values of two generations of laser-assisted indocyanine green dye angiography systems: Can we predict necrosis? Eplasty. 2014;14:e44.

6. Wyles CC, Jacobson SR, Houdek MT, Larson DR, Taunton MJ, Sim FH, Sierra RJ, Trousdale RT. The Chitranjan Ranawat Award: Running subcuticular closure enables the most robust perfusion after TKA: A randomized clinical trial. Clin Orthop Relat Res. 2016;474:47-56. 